\title{
Avoiding Cost Overruns in Construction Projects in India
}

\author{
Abdussalam Shibani, Kumar Arumugam \\ Coventry University, Coventry, United Kingdom
}

\begin{abstract}
The main aim of this paper is to identify the major reasons for cost overruns in construction projects in India as well as the critical success factors that are helping to avoid the cost overruns. For this, the existing literature is reviewed and critical success factors are identified. Based on them, survey questions and interview questions are prepared. The findings supported the proposed hypothesis, i.e., lack of certain critical success factors leads to cost overruns in construction projects in India. They also confirmed the proposed proactive and reactive strategies of some researchers. The effective critical success factors include appropriate planning in the initial stages, skills of contractors and architects, good relationship and regular coordination among client and contractor, and early contribution of contractor with the project. The ideal methods that help to reduce cost overruns include efficient planning, proper management of site and supervision of the project, suitable planning and arrangement of project, proper methods for construction, regular meetings on development of the project, and hiring proficient subcontractors and suppliers.
\end{abstract}

Keywords: India, construction, critical success factors, cost overrun

\section{Introduction}

Due to poor cost management these days, the construction industry is facing a huge amount of cost overrun. This has become quite a problem for the construction industry. Poor cost management and overrun are the huge problem and very serious issue when they come to project cost in both developed and emerging countries. This is an issue which needs attention, because projects are rarely being finished within budget (Azis, Memon, Rahman, \& Karim, 2012).

Cost is always one of the most important reasons for the success of a project. Generally, most of the main factors influencing project costs are qualitative like importance of a client on construction time, the planning ability of constructor, locating methods, and some market conditions (Elchaig, Boussabinaine, \& Ballal, 2005). A successful project is one which can overcome the cost limitations applied to it.

One of the tools that seems promising to quantify risk ratings is fuzzy risk assessment. This is when the risk effects are unclear and are defined by particular judgments instead of impartial data (Dikmen, Birgonul, \& Han, 2007).

One of the most vital tasks for completing a project successfully is to have a good management of construction cost. However, most of the times, it is not possible to achieve good cost management and the project would generally have a considerable amount of cost overrun. Based on the above mentioned factors that

Abdussalam Shibani, Ph.D., lecturer, civil engineering architecture and building, Coventry University, Coventry, United Kingdom. Kumar Arumugam, M.Sc. student in construction, project, and cost management, Coventry University, Coventry, United Kingdom. Correspondence concerning this article should be addressed to Abdussalam Shibani, Coventry University, Priory Street, Coventry, CV12FB, United Kingdom. E-mail: ab1732@coventry.ac.uk. 
cause cost overrun, 15 mitigation measures to control it have been proposed. These have been found through interviews. Based on three approaches of implementation, the 15 mitigation measures have been categorized into three parts. They are: practical, responsive, and structural strategies (Olawale \& Sun, 2010).

Contractors quoting prices based on their projected estimates are one of the most basic reasons which lead to cost overruns. Unfortunately, many times, the prices change very quickly causing the initial budget figures to become useless. In the recent past, the prices in construction industry have been highly volatile. One of the reasons for this volatility could be higher energy prices. It is observed that there was a sharp rise in prices of material like iron, steel, cement, and concrete. There have also been reports of shortages for those commodities. It is critical to consider how the vacillations could influence the expense or pace of new advancements in development industry (Burke, 2013).

To find and classify the important aspects that affect time and cost overruns in ground water projects, the items were classified into different groups. These groups were ranked and based on these ranks the order of importance of factors is identified. Based on these results, it is found that there are various factors influencing cost overruns in developing countries like Ghana. The owners, contractors, and consultants have agreed on five important causes. They are regular payment problems from agencies, bad contractor supervision, procurement of materials, bad technical performance, and increased material prices budget (Rahman, Memon, \& Karim, 2013).

There are also several other factors that have come out as interesting but not important are: bad weather and other natural calamities. These factors are natural factors. The owners group have ranked bad weather eighth and the consultants have rated it 10 and on an average it has been ranked 10. All the geological conditions have been rated low. The weather and geological factors are considered the most difficult and unknown factors, because they cannot be controlled (Frimpong, Oluwoye, \& Crawford, 2003).

\section{Factors of Cost Overrun}

There are 58 factors of cost overrun divided in to eight categories. They are: site management of contractor; management of contract and project; issues associated with labour; equipment and material; management of financial matters; communication and information; and outside reasons.

\section{Factors That Cause Severe Price Fluctuation}

The followings are some of the most common factors which cause severe price fluctuations: commodity prices throughout the world for basic supplies; the present position of the domestic economy; requirement of the quality of supplies and workmanship; and demand and supply.

\section{Macro-economic Factors}

Expense of a development would incorporate the expense of cash, the expense of work, the expense of material, and the expense of administration. The three main factors that affect cost are: fluctuation in raw material prices, manufactured materials, and cost of machineries. All three of them are market related. So it can be said that the construction industry is driven majorly by market. There is a chance that the prices in the market can change almost daily. These changes make it tough for vendors to fix a price.

One of the most important parts of a country's socio-economic growth is the construction industry. The construction industry forms quite an important part of the country's overall GDP (gross domestic product). It also develops the quality of life by creating and building new infrastructure like roads, hospitals, schools, and 
other important infrastructure. All these prove that the completion of a construction project under the expected time and meeting the expected quality is very important. However, the industry unfortunately faces chronic problems like low quality, cost overruns, time overruns, etc. very often. Out of all the problems faced by construction industry, cost overruns are probably the most important, because they can affect the overall development of a country.

This problem is a global one as the construction industry around the world exceeds the expected budget often. A global study (Flyvbjerg, Holm, \& Buhl, 2003) on construction projects has found that cost overrun is the most faced problem. It is estimated that nine out of 10 projects faced the problem with an overrun of $50 \%$ to $100 \%$. Another investigation on 87 projects conducted by Cantarelli (2009) has found that the problem of cost overrun exists in projects by an average of $10.3 \%$. Even the construction projects in developed countries face this problem. In the UK, it is found that nearly one third of all clients have complained about their projects exceeding their allocated budget. Malaysia is also another country being affected severely by this problem. It is found that only $46.8 \%$ of public sector and $37.2 \%$ of private sector projects are being finished in the allocated budget (Rahman et al., 2013).

This issue has grown so much that it has become a major concern for investors. This is an issue which needs a solution by giving it a lot of attention and performing in-depth studies on it. Cost overrun can act as a great indicator of the success of a project. By overcoming it, a firm's productivity and profitability can be understood. So, solving this issue remains one of the most important things in the construction industry.

The construction industry has been showing poor performance very often. This is one of the reasons for the cost overruns. Most of the times, cost overruns have been investigated. The reason was found to be the poorly managed cost control systems (Sriprasert, 2000). Some other sources for it were poor technological performance or inefficient equipment, improper materials from the local market, and site accidents (Koushki \& Kartam, 2004; Sayles \& Chandler, 1971).

A study performed by Olawale and Sun (2010) on the UK construction industry has found 21 major things that could factor in for cost overruns. They are: changes in design, risk and uncertainty that comes with projects, lack of proper assessment of project time, poor act of subcontractors and selected dealers, high difficulty of works, conflicts among project parties, errors in project related documentation, different interpretations of the contracts, increase of prices, funding and payment for finished works, project manager lacking proper training and experience, lack of skill in human resources, bad climate conditions, depending on imported materials, unavailability of proper software, changing interest rate, changing exchange rates, improper regulation and control, frauds in project, corruption, and changing government policies (Rahman et al., 2013).

\section{Management Factors}

On one hand, even though proper care is taken to prevent cost overruns, sometimes they are unavoidable because it is not possible to reasonably prevent them. This would include any unanticipated events. On the other hand, errors in design plan or project management can be foreseen and prevented thereby reducing a lot of chance for cost overruns. By using the project control procedure, the management can understand its present situation associated with a future position (Wilson, 1983).

According to Sriprasert (2000), cost overrun problems occur as a result of ineffective construction management and other poorly designed control systems. The carelessness of project managers can be controlled 
if the management modifies the project schedule and other estimates, according to the changes or discrepancies that could happen while the project is being implemented (Azhar, Farooqui, \& Ahmed, 2008).

\section{Business and Regulatory Environment}

The problem faced by the construction industry is that many of the players in the industry are small. They have weak financial positions and their technology is lower grade. They also lack proper organisational structure and a vision for growth. This makes these small players extremely susceptible to policies of government and changes in them.

The major cause of cost overrun associated with business and regulatory environment is the government implementing lowest bid price. This increases practices like corner cutting and usage of weak construction methods. The lowest bid price generally does not lead to best value. This is because the lowest bid price is usually made at $50 \%$ of the actual cost required. The lowest bid price system creates a lot of competition between contractors. As a result, the contractors submit a project for a bid price lower than required unintentionally or on purpose. Most of the times, this would lead to the harm for owner and contractor, as it creates cost overruns and schedule delays (Azhar et al., 2008).

\section{Methods Used to Avoid Cost Overrun}

The proactive measures are those which should be adopted in the planning stage of project. The following list talks about the classification of some common planning strategies.

The proactive strategies include: efficient planning of strategies, and management of site and supervision of the project; appropriate planning and arrangement of project; organised regulatory mechanism; and using proper methods for construction (Azis et al., 2012).

The organisational strategies include: appropriate prominence on previous experience; regular coordination between the associated parties; increasing human resources in the industry; and complete administration of contracts (Ahsan \& Gunawan, 2010).

Regular meetings on development, employing proficient subcontractors and suppliers, attributing less weight to prices, and more weight to abilities and earlier performance of contractors to improve the contracts and their procedures are some reactive and organisational strategies (Azis et al., 2012).

Using channels for perfect information and communication is a proactive and organisational strategy.

Utilization of latest technology is a proactive and reactive strategy.

Undertaking a preconstruction planning regarding the procedures and resources of project is a proactive, reactive, and organisational strategy (Azis et al., 2012).

\section{Research Methodology}

There are several differences between qualitative measurement and quantitative measurement which are mentioned below.

In quantitative examination, the alternatives have been foreordained and for the most part, a substantial number of respondents are utilized. In other words, the measurement in quantitative research should be objective, quantitative, and statistically valid. It is about the numbers in the data and it focuses on objective hard data. Generally, the size of the sample for a survey can be calculated by statisticians based on formulas which determine the size of a sample needed from a population so as to get needed accuracy in results. It is common to use samples with size that would yield in results which are at least 95 confidence intervals. This 
means that if the survey is repeated, the same results would be found 95 out of 100 times and there would be five percentage points of margin of error. Most surveys are designed in a way to produce a small amount of margin of error (Anderson, 2006; Hennink, Hutter, \& Bailey, 2011).

\section{Research Strategy}

Studies about health and health services generally use survey researches. However, the beginning of surveys can be traced back to the social surveys by social reformed conducted in Victorian Britain era. They were used to collect information regarding poverty and working class life. Even today, survey research still remains one of the most common ways to find data in applied social research. There are several different explanations for the term "survey", however it generally refers to the selection of sample space of people from a whole population and then collecting the data from each individual. Based on the information gathered from each individual from that sample of population, the researcher would come to a conclusion about the whole population (Kelly, Clark, Brown, \& Sitzia, 2003; Bendassolli, 2013).

Usually, data are collected in a standardized form. One of the common means of data collection is questionnaire or interview. Surveys help in understanding how things are at a point of time. Surveys do not attempt to control or change the variable of present condition nor do they discriminate participants. They simply depict the situations as they are. Surveys are generally suitable to descriptive studies, but they can also be used to explore aspects for a situation. An important thing to consider about surveys is that it is a research strategy and not a research method (Kelly et al., 2003).

One of the most basic types of enquiry is descriptive research which aims at observing certain phenomena at a particular point of time. In this research, a situation is analysed by describing the most important factors that are related to that situations. Most of the times, these type of researches are used to find specific parameters in population and to describe associations between various parameters (Kelly et al., 2003; Griffiths, 1996).

\section{Data Collection and Analysis}

Based on the all the projects, this section analyses the main reasons for cost overruns. This section is based on the results of all the projects. The interviewees were asked about the main reasons for cost overruns in the poor cost performance projects and the factors which avoided it in good performance projects. The interviewees were explained with the definition of cost overrun, according to this research so as to prevent their own perception from clouding the responses. The data about each case were mainly collected from the interviewees, so it is important to make sure that they knew the definitions of the research. Some information was also collected from Internet.

In this research, two renowned Indian construction companies with similar characteristics were chosen. Four different projects were selected from these companies, two with good cost performance (case 1 and case 3 ) and two with poor cost performance (case 2 and case 4) as shown in Table 1. Due to confidentiality issues, the name of the companies will not be revealed.

The answers given by the project managers, contractors, consultants, construction managers, and representatives of clients from the survey are analysed. Some information about the company has been given from the interviewees and the information given has been verified with Internet research. Four case studies were used in the research from the reputed contracting company in India. The interview protocols were sent to 
various people by the researcher. Four interviewees have acknowledged to have a one-hour semi-organised meeting. Along these lines, the whole research configuration of this thesis was focused around the four meetings which were conveyed by the two task administrators of an organisation and the review aftereffects of members. Each of the undertaking administrators was talked with around two separate activities unified with great execution and an alternate with poor execution. According to the necessities of the exploration, the interviewees must be either senior venture pioneers or at the base ought to be working at a managerial level. To guarantee that the interviewees met the necessities, a portion of the inquiries were about the points of interest of interviewees.

\section{Main Causes of Cost Overruns in Poor Performance Projects}

The followings are the main causes given for case 2 and the reason that has been given by the interviewees.

Table 1

Causes for Poor Performance in Project

\begin{tabular}{|l|l|}
\hline Cause & Reason given by interviewee \\
\hline Incompetency of the project manager & Lack of experience and skills in the manager \\
\hline Poor relation between the client and contractor & Clients had constant complaints regarding the quality of the job \\
\hline Client was unwilling to help & No proper relationship with contractor \\
\hline Client had constant changes of design & Client had lacked proper understanding regarding the project \\
\hline
\end{tabular}

The first cause given for case 2 is the incompetency of the project manager. The reason that has been given to legitimize this is the absence of experience and aptitudes in the director to deal with this sort of task. The second cause given for this venture is the poor connection between the customer and builder. The reason given for this reason is that the customers had consistent grievances with respect to the nature of the employment and they put the fault on the competency of the venture supervisor. The third cause given is that the customer was unwilling to offer assistance. The interviewees have expressed that the customer was a neighbourhood power and the individuals who were managing that extend did not give their assistance. The fourth cause given was that the customer had steady changes of outline. The meeting expressed that there were a few varieties made by the customer who brought about a period overwhelm.

So, there were three main reasons for cost overruns in this project (case 2). However, the interviewees have stated that the primary reason is considered to be the lack of competency for the project manager. The lack of competency also led to poor relationship between contractors and clients. So, it can be deduced that the lack of experience and skills in the project manager is the main cause of project manager's incompetency and the poor relationship between contractors and clients. The poor relationship combined with the changes in design has led to a significant delay. This delay has led to the increased costs of project. The interviewees have supported the view that the main problem for the project has been caused by the incompetence of the person doing that job. The interviewees have stated that the project manager has been removed and replaced which has also led to more costs.

The information mentioned in Table 2 is the main causes given for case 4 and the reason that has been given by the interviewees.

As you can see from Table 2, the first cause of poor performance for case 4 as stated by the interviewee was the wrong interpretation of contract specifications. The reason for this as stated by the interviewees was 
that the client was used to traditional forms for contracts but for this project they had to go through design and build contract. As a result in Figure 1, they had difficulty in understanding some of the specification issues. They are the necessities of employer and cost of changes. The second cause given is the client's variations in the design. The reason for this is that the client has chosen the wrong type of contract and hence the project did not have the expected flexibility of changes in design. The third cause given is poor planning initially. The reason for poor initial planning was stated as lack of some information during planning stage.

Table 2

Causes for Poor Performance in Project (Case 4)

\begin{tabular}{|l|l|}
\hline Cause & Reason given by interviewee \\
\hline Wrong interpretation of contract specifications & $\begin{array}{l}\text { Client had to go through design and build contract which was } \\
\text { new to him }\end{array}$ \\
\hline Constant variations in the design & Wrong type of contract chosen by the client \\
\hline Initial planning was poor & Lack of some information during planning stage \\
\hline
\end{tabular}

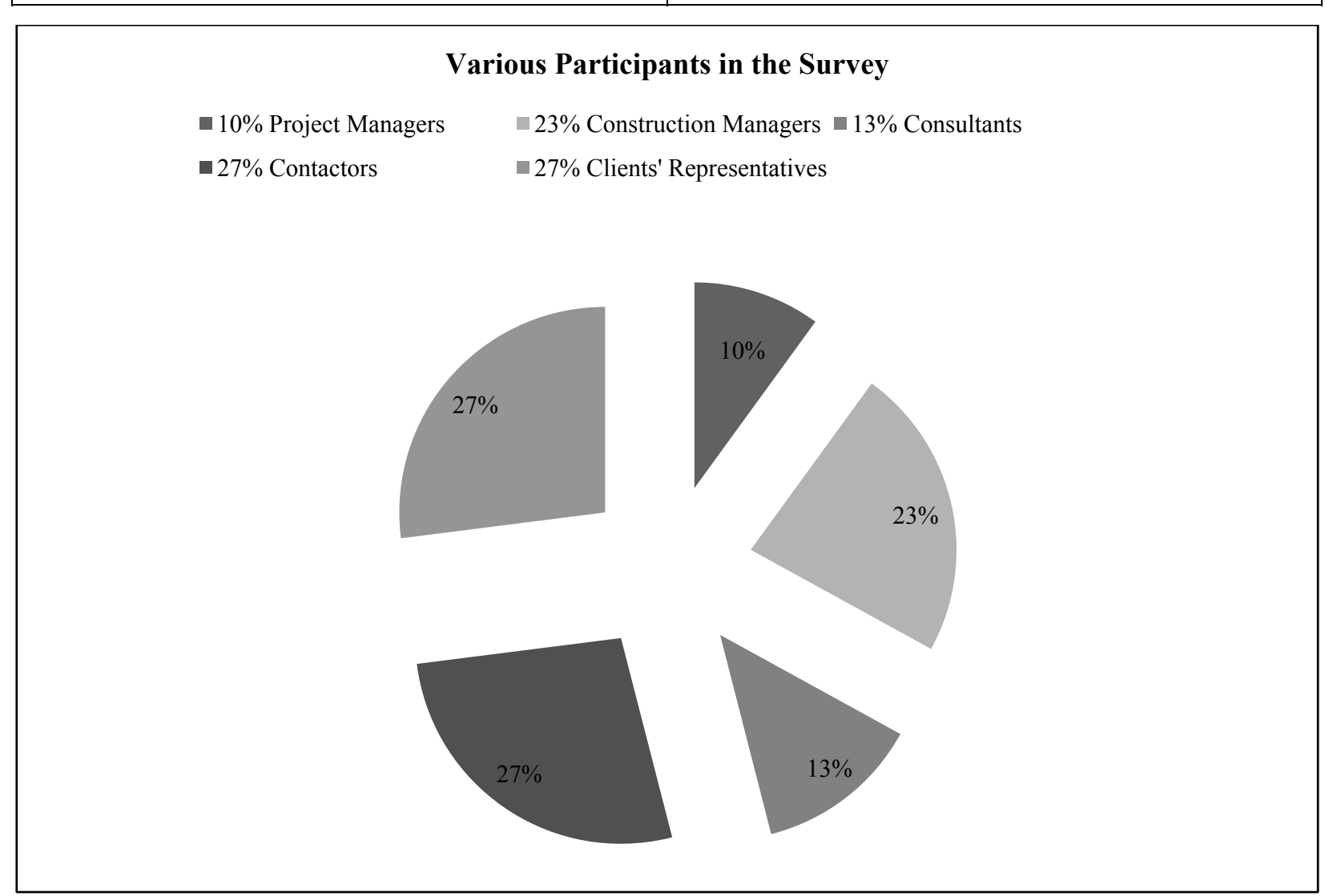

Figure 1. Percentage of various participants in the survey.

\section{Results}

In Figure 1, 52 people participated in the survey from 20 companies. Out of them, 14 are project managers, 14 are contractors, 12 are construction managers, seven are consultants, and five are representatives of client. Out of them, 33 stated that construction cost overruns and labour problems are the primary problems faced by Indian construction industry, whereas 27 stated that financial problems and others, such as material and weather 
related problems, are a major constraint in the industry, as shown in Table 3. Forty-nine out of 52 participants stated that the main reason for cost overruns is delay in materials, 45 stated delay due to land acquisitions and delay in hiring project staff, 40 claimed delay in approval of loans and their disbursement and procurement delay, and 39 stated that delay in recruiting consultants and delay in government procedures are the reasons for cost overruns in Indian construction industry, as shown in Table 4. Forty-one out of 52 stated that lack of safety measures in site and severe weather conditions leads to cost overruns, 33 stated that unanticipated ground conditions cause cost overruns, and 26 indicated that antagonistic political conditions are the site related reasons for cost overruns, as shown in Table 5. Forty-five out of 52 revealed unreasonable time schedule and non-accessibility of designs on time and 37 indicated that amendments in work due to errors in design and in execution are the project related factors that lead to cost overruns, as shown in Table 6. Forty-four out of 52 stated that improper management and supervision are the human related factors that lead to cost overruns, 41 indicated that lack of skilled workers to operate special equipment and regular change of contractors is the human related factor that leads to cost overruns, and 37 claimed that lack of proper coordination among various associated parties in the project and clashes between owners and other parties is the human related factor that leads to cost overruns, as shown in Table 7. Forty-one out of 52 stated the use of outdated construction methods is the technical issue that leads to cost overruns, 37 claimed that ineffective equipment is the technical issue that leads to cost overruns, and 33 expressed that lack of labour skills in using the machinery and financial limitations of contractors is the technical issue that leads to cost overruns, as shown in Table 8. Forty-five claimed that site costs increase the construction costs in India, 41 discovered that transportation and labour costs increase the construction costs in India, and 30 expressed that machinery costs increase the construction costs in India, as shown in Table 9.

Table 3

Various Types of Problems in the Construction Field in India

\begin{tabular}{lcc}
\hline Types of problems & Percentage & Number \\
\hline Number of participants specified various types of problems in the construction field in & $100 \%$ & 52 \\
India & $64 \%$ & 33 \\
Construction cost overruns & $64 \%$ & 33 \\
Labour problems & $52 \%$ & 27 \\
Financial problems & $52 \%$ & 27 \\
Material, weather related, etc. & & \\
\hline
\end{tabular}

Table 4

Type of Delays That Lead to Cost Overruns for the Construction Projects

\begin{tabular}{lcc}
\hline Type of delays & Percentage & Number \\
\hline Number of participants & $100 \%$ & 52 \\
Delay due to land acquisitions & $87 \%$ & 45 \\
Delay in approval of loans and their disbursement & $77 \%$ & 40 \\
Procurement delay & $81 \%$ & 42 \\
Delay in recruiting consultants & $77 \%$ & 40 \\
Delay in hiring project staff & $87 \%$ & 45 \\
Delay due to government procedures & $75 \%$ & 39 \\
Delay in material delivery & $94 \%$ & 49 \\
\hline
\end{tabular}


Table 5

Site Related Reasons for Cost Overruns in Indian Construction Industry

\begin{tabular}{lcc}
\hline Site related reasons & Percentage & Number \\
\hline Number of participants & $100 \%$ & 52 \\
Lack of safety measures in site & $79 \%$ & 41 \\
severe weather conditions & $79 \%$ & 41 \\
Unanticipated ground conditions & $64 \%$ & 33 \\
Antagonistic political conditions & $50 \%$ & 26 \\
\hline
\end{tabular}

Table 6

Project Related Reasons for Cost Overruns in Indian Construction Projects

\begin{tabular}{lcc}
\hline Project related reasons & Percentage & Number \\
\hline Number of participants & $100 \%$ & 52 \\
Unreasonable time schedule & $87 \%$ & 45 \\
Non-accessibility of designs on time & $87 \%$ & 45 \\
Amendments in work due to errors in design & $71 \%$ & 37 \\
Amendments in work due to errors in execution & $71 \%$ & 37 \\
\hline
\end{tabular}

Table 7

Human Related Factors That Lead to Cost Overruns in Indian Construction Projects

\begin{tabular}{lcc}
\hline Human related reasons & Percentage & Number \\
\hline Number of participants & $100 \%$ & 52 \\
Improper management and supervision & $85 \%$ & 44 \\
Lack of skilled workers to operate special equipment & $79 \%$ & 41 \\
Lack of proper coordination among various associated parties in the project & $71 \%$ & 37 \\
Regular change of contractors & $79 \%$ & 41 \\
Clashes between owners and other parties & $71 \%$ & 37 \\
\hline
\end{tabular}

Table 8

Technical Issues That Lead to Cost Overruns in Indian Construction Projects

\begin{tabular}{lcc}
\hline Technical issues & Percentage & Number \\
\hline Number of participants & $100 \%$ & 52 \\
Outdated construction methods & $79 \%$ & 41 \\
Ineffective equipment & $71 \%$ & 37 \\
Lack of labour skills in using the machinery & $64 \%$ & 33 \\
Financial limitations of contractors & $64 \%$ & 33 \\
\hline
\end{tabular}

Table 9

Type of Costs That Enhance the Construction Costs in Indian Construction Projects

\begin{tabular}{lcc}
\hline Type of costs & Percentage & Number \\
\hline Number of participants & $100 \%$ & 52 \\
Site costs & $87 \%$ & 45 \\
Transportation costs & $79 \%$ & 41 \\
Machinery costs & $58 \%$ & 30 \\
Labour costs & $79 \%$ & 41 \\
\hline
\end{tabular}




\section{Conclusions}

From the findings and analysis, it can be concluded that certain critical success factors are essential for the performance of construction projects and to avoid cost overruns. It is interesting that these critical success factors also affect the objectives of construction projects, like budget, performance and quality, and completion of project on time. Consequently, recognizable proof of basic achievement elements can help dodge expense invades in the development ventures. That is the reason this examination attempted to distinguish the discriminating achievement components to evade the expense invades in the development ventures in India. In spite of the fact that the discriminating achievement components may change with distinctive ventures, the vast majority of the undertakings require some regular critical success factors like legitimate arranging in the introductory stages, abilities of builders and designers, and fitting coordination in the middle of customer and foreman to succeed. Thus, it could be inferred that the findings of the study upheld the proposed theory that absence of certain critical success factors reasons expense invades in development ventures in India. In view of this, it might be presumed that the examination goals were attained to some degree.

\section{Recommendation}

The following recommendations are suggested for further research. This research mainly focused on identifying critical success factors to avoid cost overruns in the construction projects in India. Yet, finishing of projects on time and quality is also crucial in the construction industry. Hence, the influence of critical success factors on these can also be studied. Furthermore, the cross-case study revealed that certain factors led to poor performance and certain factors promoted success in the construction projects in Indian construction industry. However, all these factors are not similar to every project, though some of them are common to all projects. So, the study of specific factors that lead to either good or poor performance individually can give more accurate results and they are especially helpful for small projects. This is because, knowing how and why the contribution of these factors promote success or cause delays in construction projects can be helpful for small budget projects with fewer time completion. The multi-case study was done on four projects from two reputed companies in the construction industry. These companies are big. So, the results may vary with small companies and also different problems may be reported by them. Conducting multi-case study with more number of companies, including large and small companies, may give more accurate results. Though the survey participants included were project managers, contractors, construction managers, consultants, and representatives of clients, they were not in the same proportion. The limited sample size may also influence the results. Hence, it is suggested to include more number of participants, if similar research is done in the future. The conditions of India are different from those of developed countries as India is a developing country. So the comparison of factors, that lead to cost overruns and the success factors that are critical to a project and help to avoid cost overruns between, i.e., both developing country and one of the developed countries, may depict clearer picture.

\section{References}

Ahsan, K., \& Gunawan, I. (2010). Analysis of cost and schedule performance of international development projects. International Journal of Project Management, 28, 68-78.

Anderson, J. D. (2006). Qualitative and quantitative research (Imperial COE, 1-3).

Azhar, N., Farooqui, R. U., \& Ahmed, S. M. (2008). Cost overrun factors in construction industry of Pakistan. Proceedings from First International Conference on Construction in Developing Countries. 
Azis, A. A. A., Memon, A. H., Rahman, I. A., \& Karim, A. T. A. (2012). Controlling cost overrun factors in construction projects in Malaysia. Research Journal of Applied Sciences, Engineering and Technology, 5(8), 2621-2629.

Bendassolli, P. F. (2013). Theory building in qualitative research: Reconsidering the problem of induction. Forum: Qualitative Social Research, 14(1), 23-38.

Burke, R. (2013). Project management: Planning and control techniques (5th ed.). Hoboken, NJ: Wiley.

Cantarelli, C. C. (2009). Cost overrun in Dutch transportation infrastructure projects. Bijdrage aan het Colloquium Vervoersplano Speurwerk (Contribution to the transport planning research colloquium). Retrieved from http://www.cvs-congres.nl/cvspdfdocs/cvs09-156.pdf

Dikmen, I., Birgonul, M. T., \& Han, S. (2007). Using fuzzy risk assessment to rate cost overrun risk in international construction projects. International Journal of Project Management, 25, 494-505.

Elchaig, T., Boussabinaine, A., \& Ballal, T. (2005). Critical determinants of construction tendering costs: Quantity surveyors' standpoint. International Journal of Project Management, 23, 538-545.

Flyvbjerg, B., Holm, M. K. S., \& Buhl, S. L. (2003). How common and how large are cost overruns in the transport infrastructure projects? Transport Review, 23, 71-88.

Frimpong, Y., Oluwoye, J., \& Crawford, L. (2003). Causes of delay and cost overruns in construction of groundwater projects in developing countries: Ghana as a case study. Journal of Project Management, 21, 321-326.

Griffiths, F. (1996). Qualitative research: The research questions it can help answer, the methods it uses, the assumptions behind the research questions and what influences the direction of research: A summary of the panel discussion at the conference "Exploring qualitative research in general practice". Family Practice, 13, 27-30.

Hennink, M., Hutter, I., \& Bailey, A. (2011). Qualitative research methods. London: SAGE Publications.

Kelly, K., Clark, B., Brown, V., \& Sitzia, J. (2003). Good practice in the conduct and reporting of survey research. International Journal for Quality in Health Care, 15(3), 261-266.

Koushki, P. A., \& Kartam, N. (2004). Impact of construction materials on project time and cost in Kuwait. Engineering, Construction and Management. Economics Journal, 11(2), 126-132.

Olawale, Y. A., \& Sun, M. (2010). Cost and time control of construction projects: Inhibiting factors and mitigating measures in practice. Construction Management and Economics, 28(5), 509-526.

Rahman, I. A., Memon, A. H., \& Karim, A. T. A. (2013). Significant factors causing cost overruns in large construction projects in Malaysia. Journal of Applied Sciences, 13(2), 286-293.

Sayles, L. R., \& Chandler, M. K. (1971). Managing large systems. New York: Harper and Row.

Sriprasert, E. (2000). Assessment of cost control system: A case study of Thai construction organisations (M.S. thesis, Asian Institute of Technology, Bangkok).

Wilson, R. M. S. (1983). Cost control handbook. Essex: Gower. 